OPEN ACCESS

Edited by:

Jose M. Gonzalez,

University of La Laguna, Spain

Reviewed by:

David Schleheck

University of Konstanz, Germany

*Correspondence:

Kai Tang

tangkai@xmu.edu.cn

Specialty section:

This article was submitted to

Aquatic Microbiology,

a section of the journal

Frontiers in Marine Science

Received: 13 March 2020

Accepted: 07 April 2020

Published: 15 May 2020

Citation:

Tang K (2020) Corrigendum: Chemical

Diversity and Biochemical Transformation of Biogenic Organic

Sulfur in the Ocean.

Front. Mar. Sci. 7:280

doi: 10.3389/fmars.2020.00280

\section{Corrigendum: Chemical Diversity and Biochemical Transformation of Biogenic Organic Sulfur in the Ocean}

\author{
Kai Tang* \\ State Key Laboratory of Marine Environmental Science, Fujian Key Laboratory of Marine Carbon Sequestration, College of \\ Ocean and Earth Sciences, Xiamen University, Xiamen, China
}

Keywords: microbe, organic sulfur, gene, sulfur cycle, transformation

\section{A Corrigendum on}

Chemical Diversity and Biochemical Transformation of Biogenic Organic Sulfur in the Ocean by Tang, K. (2020). Front. Mar. Sci. 7:68. doi: 10.3389/fmars.2020.00068

In the original article, there was an error "Two major sulfoglycolytic pathways, the sulfo-Embden-Meyerhof-Parnas pathway (originally found in E. coli) and the sulfo-Entner-Doudoroff pathway (originally found in Pseudomonas putida SQ1) (Roy et al., 2003; Denger et al., 2014), have been shown to degrade SQ in certain marine bacteria (Roy et al., 2003). These pathways are analogous to the classic glycolysis pathways (Figure 2) (Felux et al., 2015). The sulfo-Embden-Meyerhof-Parnas pathway and the sulfo-Entner-Doudoroff pathway yield the C3-organosulfonate products DHPS and sulfolactate (Figure 2), respectively (Roy et al., 2003; Denger et al., 2014).”

A correction has been made to "BIOCHEMICAL REACTION NETWORK FOR ORGANIC SULFUR," "Sulfonate Metabolisms," "Paragraph Number 1":

"SQ has been shown to be degraded by certain aerobic as well as anaerobic bacteria (Roy et al., 2003; Denger et al., 2012, 2014; Felux et al., 2015; Burrichter et al., 2018) and two major sulfoglycolytic pathways, the sulfo-Embden-Meyerhof-Parnas pathway (originally found in E. coli) and the sulfo-Entner-Doudoroff pathway (originally found in Pseudomonas putida SQ1) have been described (Denger et al., 2014; Felux et al., 2015). These pathways are analogous to the classic glycolysis pathways (Figure 2) (Felux et al., 2015). Bacterial SQ degradation yields the C3-organosulfonate products DHPS and sulfolactate (Figure 2) (Roy et al., 2003; Denger et al., 2012, 2014; Felux et al., 2015; Burrichter et al., 2018).”

And the (Denger et al., 2012) citation has now been inserted in.

The authors state that this does not change the scientific conclusions of the article in any way. The original article has been updated. 


\section{REFERENCES}

Burrichter, A., Denger, K., Franchini, P., Huhn, T., Müller, N., Spiteller, D., et al. (2018). Anaerobic degradation of the plant sugar sulfoquinovose concomitant with H2S production: Escherichia coli K-12 and Desulfovibrio sp. strain DF1 as co-culture model. Front. Microbiol. 9:2792. doi: 10.3389/fmicb.2018.02792

Denger, K., Huhn, T., Hollemeyer, K., Schleheck, D., and Cook, A. M. (2012). Sulfoquinovose degraded by pure cultures of bacteria with release of C3organosulfonates: complete degradation in two-member communities. FEMS. Microbiol. Lett. 328, 39-45. doi: 10.1111/j.1574-6968.2011.02477.x

Denger, K., Weiss, M., Felux, A., Schneider, A., Mayer, C., Spiteller, D., et al. (2014). Sulphoglycolysis in Escherichia coli K-12 closes a gap in the biogeochemical sulphur cycle. Nature 507, 114-117. doi: 10.1038/nature12947
Felux, A., Spiteller, D., Klebensberger, J., and Schleheck, D. (2015). Entnerdoudoroff pathway for sulfoquinovose degradation in Pseudomonas putida SQ1. Proc. Natl. Acad. Sci. U. S. A. 4298-4305. doi: 10.1073/pnas.1507049112

Roy, A. B., Hewlins, M. J. E., Ellis, A. J., Harwood, J. L., and White, G. F. (2003). Glycolytic breakdown of sulfoquinovose in bacteria: a missing link in the sulfur cycle. Appl. Environ. Microbiol. 69, 6434-6441. doi: 10.1128/AEM.69.11.6434

Copyright $\odot 2020$ Tang. This is an open-access article distributed under the terms of the Creative Commons Attribution License (CC BY). The use, distribution or reproduction in other forums is permitted, provided the original author(s) and the copyright owner(s) are credited and that the original publication in this journal is cited, in accordance with accepted academic practice. No use, distribution or reproduction is permitted which does not comply with these terms. 